\title{
Both babies with sirenomelia' in twin pregnancy: a case report and review of literature
}

\section{Soham Chowdhury*, Sarmila Kundu, Satyendu Sekhar Manna, Anita Das}

Department of Obstetrics \& Gynaecology, Malda Medical College and Hospital, Malda, West Bengal, India

Received: 30 March 2015

Accepted: 09 May 2015

\section{*Correspondence:}

Dr. Soham Chowdhury,

E-mail: sohamobg@yahoo.com

Copyright: (C) the author(s), publisher and licensee Medip Academy. This is an open-access article distributed under the terms of the Creative Commons Attribution Non-Commercial License, which permits unrestricted non-commercial use, distribution, and reproduction in any medium, provided the original work is properly cited.

\begin{abstract}
Sirenomelia, also called as 'Mermaid syndrome', is a rare congenital malformation of uncertain aetiology. It is characterised by fusion of the lower limbs and commonly associated with severe urogenital and gastrointestinal malformation. We report a case of twin pregnancy with both babies had sirenomelia. No previous case of 'both babies with sirenomelia' in twin pregnancy has been reported till date.
\end{abstract}

Keywords: Twin, Sirenomelia, Mermaid syndrome, Oligohydramnios

\section{INTRODUCTION}

Sirenomelia, a very rare congenital anomaly, in which fused lower limbs, rudimentary or absent genitalia and absent excretory pores result in fish-tail like external appearances of lower extremity of the foetus resembling the 'mermaids' of Greek mythology, hence commonly known as 'mermaid syndrome'. It is equally been referred as symmelia, sympodia monopodia, sympus ${ }^{2}$. The reported incidence of sirenomelia is approximately 1 in $100000 .^{2}$ It is a lethal congenital condition having internal anomalies. ${ }^{1}$ Many of these cases reported worldwide. ${ }^{3}$ We are presenting a unique case where both babies born out of twin pregnancy had sirenomelia. After a thorough search of literatures, to best of our knowledge, no previous case of 'both babies with sirenomelia' in twin pregnancy has been reported till date.

\section{CASE REPORT}

Mrs. LP, 19 years, G1P0+0, married for $1 \mathrm{yr}$, from Balurghat, of poor socioeconomic status, conceived spontaneously, admitted at Malda Medical College and
Hospital, West Bengal at 32 weeks of gestational age with complains of diminished foetal movement being referred from local health facility. Her antenatal care was inadequate. USG was not done. It was not a case of consanguineous marriage. There was neither any history of twining or congenital anomaly in the family nor any family history of diabetes mellitus. There was no history of exposure to toxins or drugs or any significant febrile episode in antenatal period. Her antenatal blood glucose and $\mathrm{Hb} \%$ were normal. On admission USG revealed twin live foetal gestations with both foetuses on transverse lie, $2^{\text {nd }}$ foetus having an encephalocoele. USG revealed corroborated gestational age but gross oligohydramnios and moderate IUGR. Unfortunately no other anomaly was commented. Decision of LUCS was taken as both foetuses were in transverse lie with severe oligohydramnios. LUCS was done with Inj. Betamethasone given, considering at least one salvageable baby. But both babies delivered out of single amniotic sac (monochorionic monoamniotic). Both had fused lower extremities, absent genitalia and absent anal and urethral orifices. The lower extremity of one baby was simply tail like (simpus apus). The other baby also 
had single fused tapering lower extremity, having two legs fused together side to side, with a single foot directed posteriorly (simpus unipus) with few digits. Both babies had prominent infraorbital folds, hypertelorism, abnormal ear lobation, small receding chin and flattened nose tip suggestive of 'Potter's facies'. One baby had an occipital encephalocoele. They were respectively weighed $1.2 \mathrm{~kg}$ and $1 \mathrm{~kg}$., non-vigorous with very poor APGAR scores. Both were connected to a single placenta with two different cords. Both cords were 2 vessels cords suggestive possibility of single umbilical artery in each cord. They were quickly shifted to SNCU but died within hour. Patient party removed the bodies and refused further post-mortem investigation (autopsy and radiological) as such congenital malformations are considered as effect of evil-spirit from their local belief.

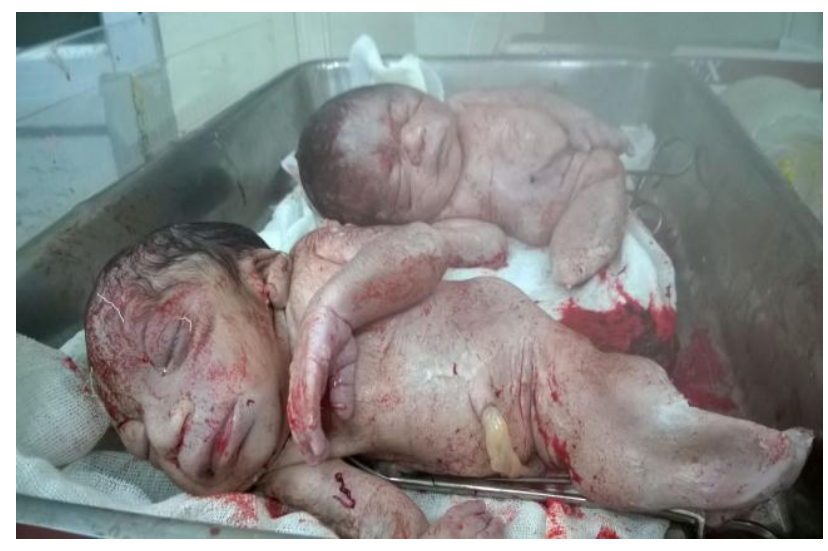

Figure 1: Both babies with sirenomelia: fused lower limbs, Potter's facies, absent genitalia.

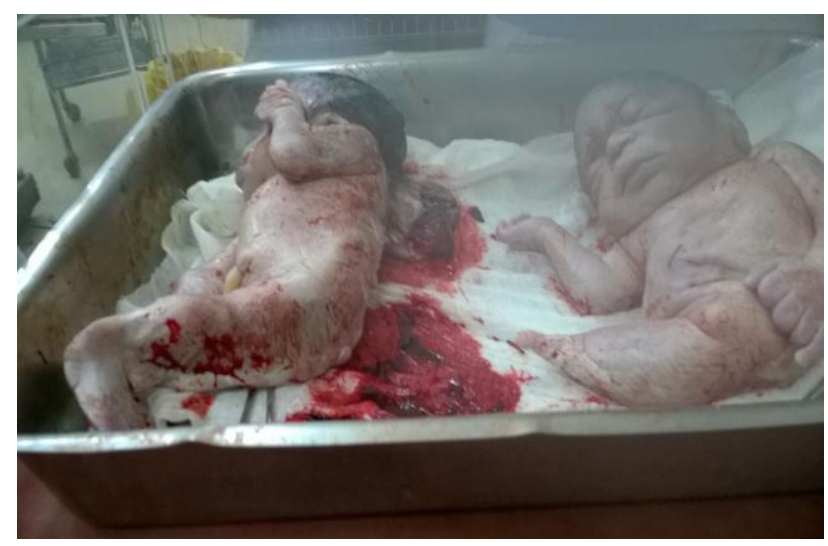

Figure 2: Both babies had imperforate anus. One baby had encephalocoele (ruptured).

\section{DISCUSSION}

Sirenomelia is an abnormal development of the caudal region of the body involving varying degree of fusion of the lower limbs with or without bony defect. ${ }^{4}$ It is commonly associated with renal agenesis, absent or malformed external and internal genitalia, a single umbilical artery, imperforate anus, and a blind ending large intestine. ${ }^{4}$ Other abnormalities found are double inferior vena cava and angiomatous lumbosacral myelocystocoele. ${ }^{4}$ Most cases of sirenomelia result in stillbirth. ${ }^{4}$ Those born alive usually die within days of birth because of complications associated with abnormal kidney and bladder development and function. ${ }^{4}$ Only very few number of babies with sirenomelia but without serious urogenital anomalies, have been reported to survive beyond the neonatal period ${ }^{5}$ after repeated surgeries, renal transplantation and life support. There are reports of successful orthopaedic surgeries to correct limb defects. ${ }^{6}$ In our case both babies succumbed to death within hour. Gross oligohydramnios suggested severe urological anomalies. These two babies demonstrated the features of 'Potter's facies', often associated with sirenomelia. This facial deformation is a sequence due to oligohydramnios.

Maternal age below 20 years is strongly associated ${ }^{7}$ with sirenomelia as in our case. Maternal diabetes often weekly associated with it. ${ }^{2}$ Twin, mainly monozygotic twin $^{2}$ has been frequently associated (more than 100-150 times), where only one foetus had sirenomelia. In our case it was monochorionic monoamniotic twin pregnancy. Some heavy metals ${ }^{8}$ exposure may be causally associated. Animal study confirmed the association with retinoic acid, cocaine or irradiation. ${ }^{8}$ Intracytoplasmic sperm injection is also considered as a causal factor. ${ }^{8}$ None of these were associated in our case.

There are several different hypotheses for the etiopathogenesis of sirenomelia. 'Vascular steal theory' is one such hypothesis. ${ }^{1,9}$ Abnormal abdominal artery arising from high up in the aorta, shunts blood towards the placenta, results in poor perfusion of the caudal part. Hypoplasia of the vasculature distal to the artery leads to complete/incomplete agenesis of the caudal structures. Single umbilical artery in both babies in our case supports this theory. But there are cases without vascular abnormalities. Some researchers suggest sirenomelia is a severe form of caudal regression syndrome and VACTERL ('vertebral defects, anorectal atresia, cardiac abnormalities, tracheo-oesophageal fistula, renal and limb abnormalities') association due to overlapping features. ${ }^{4}$ Hypothesis suggestive of defective blastogenesis in $3^{\text {rd }}$ week of intrauterine life at the phases of gastrulation results in dysgenesis of caudal region of the fetus. ${ }^{1}$ There is genetic hypothesis also. Sirenomelia occurs in mice lacking Cyp26a1, an enzyme that degrades Retinoic Acid (RA), causes reduced Bmp signalling in the caudal embryonic region and excess RA. ${ }^{1}$ But sporadic nature of human sirenomelia is a contrast of genetic-model for mice $^{1}$. Duhamel proposed the lower limb fusion theory and fixed criteria for 'mermaid syndrome'. ${ }^{10}$

Some authors describes three simple types, simpus apus (no feet, one tibia, one femur), simpus unipus (one foot, two femur, two tibia, two fibula), simpus dipus (two feet and two fused legs (flipper like). ${ }^{6}$ Sirenomelia is classified on the basis of skeletal elements present in lower extremity ${ }^{1}$, given in Table 1 . 
Table 1: Classification of sirenomelia.

\begin{tabular}{|ll|}
\hline Type & Characteristics \\
\hline I & All thigh and leg bones are present \\
\hline II & Single fibula \\
\hline III & Absent fibula \\
\hline IV & Partially fused femurs, fused fibulae \\
\hline V & Partially fused femurs \\
\hline VI & Single femur, single tibia \\
\hline VII & Single femur, absent tibia \\
\hline
\end{tabular}

\section{CONCLUSION}

Sirenomelia is a rare congenital anomaly, usually incompatible with life. Severe oligohydramnios should raise the suspicion of sirenomelia. A proper antenatal check-up with ultrasound examination should diagnose the cases in antenatal period. If detected early, voluntary termination of pregnancy can be advised in this nearlethal congenital malformation. Though there are few reports of infant wellbeing, newborn survival in such malformed babies is still a far-reached goal in our resource-poor set-up. There is scope of further research in such rare congenital anomalies.

Funding: No funding sources Conflict of interest: None declared

Ethical approval: Not required

\section{REFERENCES}

1. Garrido-Allepuz C, Haro E, González-Lamuño D, Martínez-Frías ML, Bertocchini F, Ros M. A clinical and experimental overview of sirenomelia: insight into the mechanisms of congenital limb malformations. Dis Model Mech. 2011 May;4(3):289-99.

2. Morfaw F, Nana PN. Sirenomelia in a Cameroonian woman: a case report and review of the literature. Version 2. F1000Res. 2012;1:6.

3. Di Lorenzo M, Brandt ML, Veilleux A. Sirenomelia in an identical twin: a case report. J Pediatr Surg. 1991 Nov;26(11):1334-6.

4. Ugwu RO, Eneh AU, Wonodi W. Sirenomelia in a Nigerian triplet: a case report. J Med Case Rep. 2011;5:426.

5. Clarke LA, Stringer DA, Fraser GC, Yong SL. Long term survival of an infant with sirenomelia. Am J Med Genet. 1993;45:292-6.

6. Mahapatra S, Ambasta S. Sirenomelia: a case report. Int J Case Rep Images. 2014;5(9):638-41.

7. Dharmraj M, Gaur S. Sirenomelia: a rare case of foetal congenital anomaly. J Clin Neonatol. 2012 Oct-Dec;1(4):221-3.

8. Pal S, Biswas R, Danda D, Chattopadhyay JC, Danda TK. Sirenomelia: Mermaid syndrome. Int J Anat Res. 2014;2(4):689-91.

9. Stevenson RE, Jones KL, Phelan MC, Jones MC, Barr M Jr, Clericuzio C, et al. Vascular steal: The pathogenic mechanism producing sirenomelia and associated defects of the viscera and soft tissues. Pediatrics. 1986;78(3):451-7.

10. Duhamel B. From the mermaid to anal imperforation: the syndrome of caudal regression. Arch Dis Child. 1961;36:152-5.

DOI: $10.18203 / 2320-1770 . i j r \operatorname{cog} 20150126$

Cite this article as: Chowdhury S, Kundu S, Manna SS, Das A. Both babies with sirenomelia' in twin pregnancy: a case report and review of literature. Int J Reprod Contracept Obstet Gynecol 2015;4:908-10. 